\title{
The Agrarian City in the age of Planetary Scale Computation: Dynamic System Model and Parametric Design Model for the introduction of Vertical Farming in High Dense Urban Environments in Singapore
}

\author{
Tabony Aiman'; Llabres-Valls Enriqueta ${ }^{2}$ \\ ${ }^{1} \mathrm{PhD}$ Candidate at Architectural Association, London \\ ${ }^{2}$ Lecturer at Bartlett School of Architecture, University College London, United Kingdom \\ aimantabony@gmail.com, e.llabres-valls@ucl.ac.uk
}

\begin{abstract}
Current conditions related to food security lead to study alternative forms of food production in cities such as vertical urban farming in high dense urban environments. This paper discusses the development of the Innovate UK award-winning project consisting of a dynamic system model that generates a large dataset of artificial environments linked to a multi-objective optimization model of urban massing for one square kilometer of development along the coastline of Singapore. The scope of the model is to reach the highest level of self-sufficiency in relation to food consumption.

The model operates, as a dynamic system constituted of different subsystems including transport, water, agriculture and energy. These systems dynamically interact among each other and with their environment, which is considered the primary source of energy and the main provider of hydrological resources. A large dataset of artificial environments is created employing a Dynamic System Modelling Software; this includes different scenarios of environmental stress such as sea level rise, population growth or changes on the demand side. Such dataset of artificial environments serves as an input for the multi-objective optimization model that employs genetic algorithms to produce a large data set of urban massing including the distribution of a range of food production technologies in relation to pre-established conditions for vertical urban agriculture and compatibility with other urban programs. Connectivity, solar radiation and visual cones are the fitness criteria against which the model has been tested. This paper assesses whether artificial environments further away from the pareto front produce populations of urban design solutions that respond to extreme environmental conditions and environmental shocks.
\end{abstract}

Keywords: Urban Design; Ecology; Vertical Farming; Dynamic System Modelling; Evolutionary Algorithms; Relational Urban Model

\section{Introduction}

Food security is an urban challenge that will be exacerbated by population growth and climate change. Historically, urbanization emerged from the development of agriculture. Settlements were well embedded in their immediate environment, developing distinctive morphologies and a metabolic infrastructure that adapted to the local conditions. Currently, extensive agriculture in remote areas sources global cities. According to UN by 2050 the world population will reach 9.5 billion people, this increase of 2.5 billion requires an additional of 850 million hectares of arable land.(Alexandratos \& Bruinsma, 2012; Despommier, 2009). The impossibility of taking away such quantity from other ecosystems implies to reconsidering the existing production system that is supporting our cities.

Back to the end of XIXC, when agriculture started to intensify and concentrate in remote areas a group of architects addressed food production in cities. Two seminal projects were developed at that time: (1) Frank Lloyd Wright's "Broadacre City" and (2) Ludwig Hilberseimer's "New Regional Pattern" (Hilberseimer, 1949; Wright, 1932). Both projects advocated for decentralized 
and integrated agriculture within cities. Some of the principles from "The Agrarian City" could be relevant today; particularly, Hilberseimer's interdependent unit of production and its integration in the ecology of the region. Down to the scale of the technology, the ecologist Despommier argued that, with the same footprint, indoor farming techniques and controlled-environment agriculture technology could yield much more food than outdoor farming (Despommier, 2009). The liability of this technology lies in the fact that vertical farming requires much more energy due to the need of artificial lighting and climate control system. Numerous studies have been developed at the architectural scale; among these are Harvest Green Tower and Sky Farm in Canada, Plantagon in Sweden and La Tour Vivante in France.(Al-Kodmany, 2018). A large majority of these look at vertical farming as an architectural problem focusing on the relationship between architectural morphology, solar radiation, energy dynamics and the organization of the production system at the scale of the building. However, looking at vertical farming from this perspective has limitations in order to understand whether vertical farming as a production system can make a significant impact at the city scale. In order to cover this gap, it is necessary to bridge two scales, one that is related to the interrelated unit of production and its relationship with the ecology of the city along the lines described in Hilberseimer model and the other related to scale of the technology described by Despommier.

This paper aims to cover this gap by bridging the two scales mentioned above and looking at the feasibility of implementing vertical farming at the scale of the urban block. It will do so by discussing the development of the Innovate UK award-winning project consisting of a dynamic system model that generates a large dataset of artificial environments linked to a multi-objective optimization model of urban massing for one urban block in Singapore. The scope of the model is to reach the highest level of self-sufficiency in relation to food consumption.

The model operates, as a dynamic system constituted of different subsystems including water, agriculture and energy. These systems dynamically interact among each other and with their environment, which is considered the primary source of energy and the main provider of hydrological resources. A large dataset of artificial environments is created, employing a Dynamic System Modelling Software; this includes different scenarios of environmental stress such as population growth or changes on the demand side. Such dataset of artificial environments serves as an input for the multi-objective optimization model. This employs genetic algorithms to produce a large data set of urban massing including the distribution of vertical farming technologies. Solar radiation is the main fitness criteria against which the model has been tested. The integration of these two methods could increase the potential of the urban blocks to function as productive system. The experiment demonstrates that it is possible to achieve self-sufficiency by integrating vertical farming as integral part of the urban block. Five hours of sunlight at the ground level are the optimum value generated by the model.

This paper is structured in three sections: Section (1) The agrarian city in the age of planetary scale computation; discusses vertical farming as a production system building a comprehensive approach that ranges from the scale of the region to the scale of the technology. In addition, taking in consideration the city as a dynamic complex system and the socio-economic implications of what Benjamin Bratton defines the age of planetary scale computation. Section (2) introduces the design methodology consisting of three sub-sections: (2.1) The study of the technical advantages and constraints of vertical farming and how these set the principles for the urban morphology in the parametric urban model. (2.2) The use of dynamic System Modelling for the development of artificial environments in Singapore. (2.3) The use of evolutionary algorithms for the development of urban morphology linked to specific conditions defined by the artificial environments developed in section (2.2) section (3) findings and conclusion. 


\section{The Agrarian City in the Age of Planetary Scale Computation.}

In 1990s the ecologists Dickson Despommier suggested Vertical Farming as an alternative to conventional agriculture production (Despommier, 2009). The defining feature of this technology is to increase production without additional footprint by stacking greenhouses on top of each other. Numerous attempts have been done in order to implement it in the city but the predominant production system is still based on centralization and intensification of arable land. This section discusses the potentials and drawbacks of this technology taking in consideration the socio-economic aspects as well as technical, morphological and urban constraints related to vertical farming. The aim is to define the principles of a production system that can have an impact at the city scale by looking at what is the appropriate type of urban documentation for the development of the system, the interdependent unit of production and which urban protocols, parameters and regulations are necessary in order to implement vertical farming as a production system in Singapore.

By the end of the XIXC, industrial manufacturing and the development of railway systems set the seeds for the centralization and intensification of agriculture in the countryside. Intensification started to show its negative effects including soil exploitation, resources depletion, air pollution, slums and cities' disintegration. In response to that, there were a number of ambitious urban planning projects that explicitly attempted to integrate agriculture within the city. Later named as the agrarian city, the projects focused on urban agriculture and its implication on the city form and its structure (Waldheim, 2010). One of these projects was carried out by Ludwig Hilberseimer - the decentralized city (1944) - where he proposed the principle of decentralization and integration of agriculture and industry. He argued for the region as the appropriate area for planning interference, "an interrelated part of country, a natural unit, self-contained by reasons of geographical advantages, natural resources, soil condition, natural and man-made routes, developed and used by population". In his model, the region is considered an organism in which the whole is related to the parts, and the parts related to the whole; aiming to reach a balanced production and support life (Hilberseimer, 1949).

One useful idea is that of the interrelated units of production constituting a whole. In the contemporary scenario, the units must be redefined according to site-specific conditions and taking in consideration the introduction of new technologies. Despommier's concept of vertical farming consists of stacking layers of crops under rigorously controlled conditions. This implies less required land and therefore the size of the interdependent unit of production should be smaller. Here, the interdependent unit of production is an average Singaporean urban block of $350 \times 220$ meters, $40 \%$ is considered green area and the average population is 8500 residents/block.

Other advantages of Vertical Farms technology are: (1) they use significantly less water thanks to the irrigation techniques available today (drip irrigation, aeroponics and hydroponics), (2) pesticides and herbicides are no longer needed and (3) they can efficiently recycle organic waste and wastewater (Rassia et al., 2012). The building typology of vertical farms can vary between high-rise buildings, underground spaces, facades and rooftop greenhouses. The main disadvantage of this technology is the economic feasibility in relation to the energy demand. In a scenario where the vertical farm is lit only with artificial light the energy demand is much higher than other methods of production. Therefore, the feasibility of the vertical farm relies on how much natural light and renewable energy it receives in relation to the footprint and it will be described in detail in the following section (Kalantari et al., 2017): 

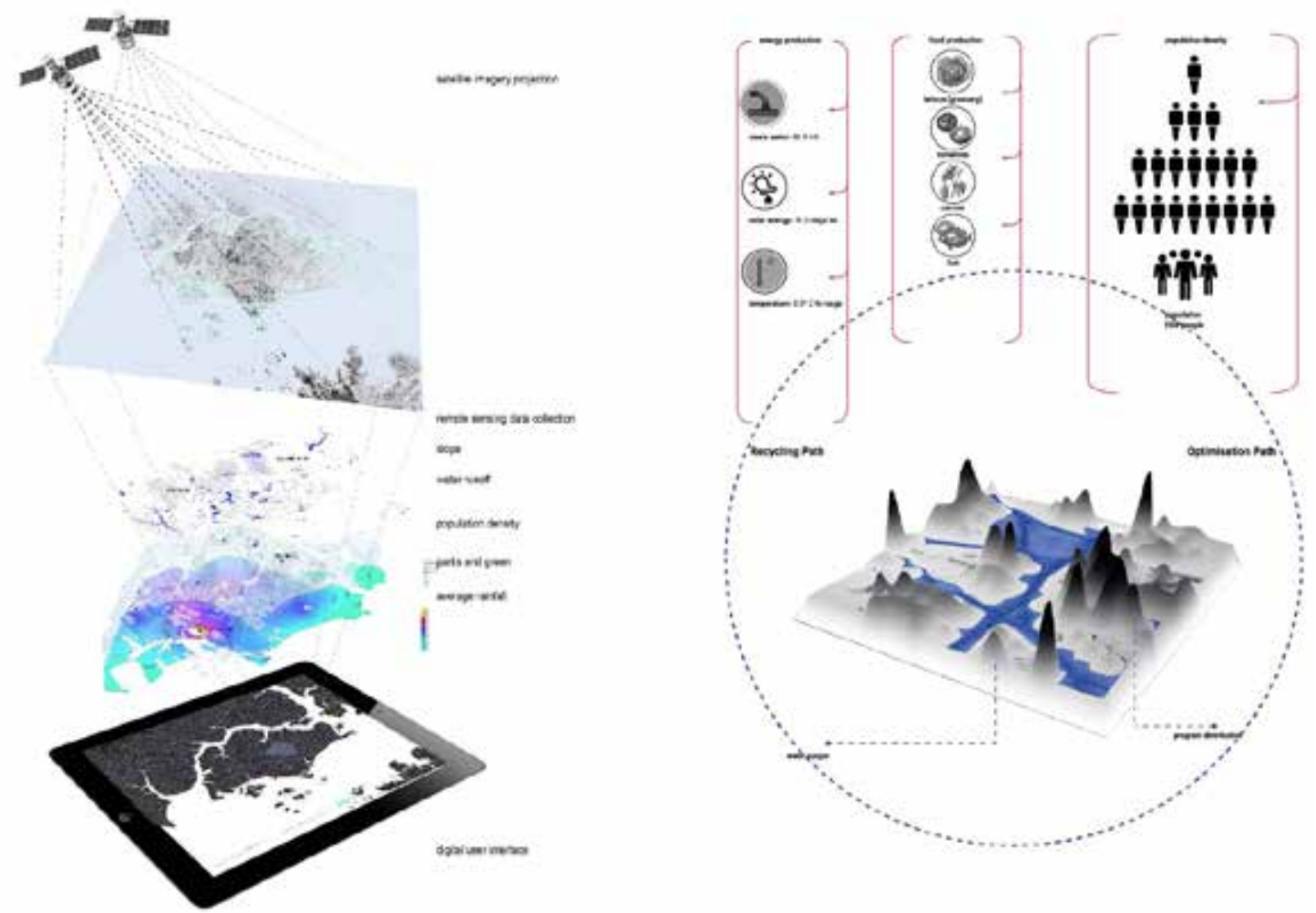

Figure 02.

Based on general system theory developed in the fifties and sixties, the notion of city as a system replaced the traditional conception of the city as physical structures and aesthetic organization. A system is composed of a set of interacting subsystems with hierarchal organization embodying feedback and keeping the system in equilibrium within its boundaries. However, city systems are more likely to be in disequilibrium or even classed as far from equilibrium (Batty, 2013). This notion exhibits the key feature of complex systems that is the dynamic evolving nature of the system itself. Thus, cities can be seen as dynamic adaptive complex systems composed of constellations of interactions, communications, flows and networks ; showing the characteristics of complex dynamic system including scaling, self-similarity and far-from-equilibrium structures (Batty, 2008). Complex systems exhibit three distinctive properties: Firstly, the complex collective behavior: the collective actions of the systems' components that give rise to the emergence of behavioral patterns of the system, commonly known by "the action of the whole is more than the sum of action of the parts". Secondly, signaling and information processing; systems and their components produce and use information from both their internal and external environments (Mitchell, 2011). Lastly, adaptation, complex systems change their behavior and strategies to adapt in response to interaction with other components through evolutionary or learning processes. These three properties, collective behavior, information processes and adaptation are the core concepts in dynamic systems modelling.

Considering the city as a dynamic complex system, places the emphasis on the continuously changing behavior over different timescale. Thus, the appropriate modelling framework is one based on Dynamic System Modelling (DSM). The (DSM) approach was developed in the fifties by Jay W. Forrester, at the MIT (Forrester, 1997). It is used for a broad spectrum of applications including modelling complex ecological and economic systems. This method simulates the system by mathematically solving the set of linear equations that describe the system (Ljung, 1998) (DSM). However, the ability to represent spatial conditions and morphology is limited because it cannot effectively describe the detailed 
distribution and situations of the spatial factors in the urban system. In order to bridge this gap, and relate the production system to the urban morphology the (DSM) is linked to a parametric design software. The purpose of linking these two modelling tools is to understand the complex dynamics both quantitative and qualitative involving the introduction of vertical farming in the city.

Overall, this section defines the principles of the model proposed in this paper. The proposed model departs from an interdependent unit of production that is defined by the site-specific conditions and the constraints of the technology, which in this case is the vertical farming. This unit is interdependent with other units using a digital form of urban documentation called Relational Urban Model. (RUM) allows real time interplay with urban form in such a way that users can understand interdependencies between different spatial and non-spatial components of the production system (Llabres \& Rico, 2012). And Lastly, considering cities as dynamic adaptive complex systems, the viability of the unit is tested using a Dynamic System Model linked to a parametric design model.

\section{DESIGN METHODOLOGY}

The design methodology is structured in three sub-sections: (1) The study of the technical advantages and constraints of Vertical Farming and how these set the principles for the urban morphology in the parametric urban model. (2) The use of Dynamic System Modelling for the development of artificial environments in Singapore. (3) The use of Evolutionary Algorithms for the development of urban morphology linked to specific conditions defined by the artificial environments developed in section (2).

\subsection{Vertical Farming: from Energy Flows to Principles for Urban Morphology}

Energy flows (demand and generation) set the principles for Vertical Farming Design. This section discusses how the understanding of the energy flows can influence the design of the building morphology and the urban block. Vertical Farms need to capture light to cultivate the crops indoors and pump water throughout the building for the hydroponics. The amount of water needed for hydroponic agriculture is estimated to be 10.71 liters per square meter. Contingent on the type of crop, 200-600 liters of water is needed to provide 1 kilogram of dry product (Kalantari et al., 2017). In addition to rainwater Vertical Farms can also re-use grey water; which once filtered, it can be used for watering indoor or outdoor plants. Water is pumped to the top from which it falls down and irrigate the crops through gravity. The water that evaporates inside the farm can be used again by dehumidification. Renewable energy can be produced by distributing solar panels on the roof and on one side of the facade. ETFE (Ethylene Tetra Fluoro Ethylene) is a material with the adequate transparency and the thermal rate needed to raise the amount of sunlight needed (Kalantari et al., 2017).

Light system needs to be highly efficient for photosynthesis of plants. The light required in closed space for vegetation growth is about 18 hours a day. In addition to natural daylight, vertical farms need daylight concentration, direction and distribution strategies. During the day, much of the light energy needed for the plants to grow is reflected when touches the glass. When the light touches plants at a low angle, less light is absorbed in any square inch of the leaf. Solar energy needs can be gathered by a system of mirrors from the buildings around the city. However, in the majority of the cases, there is a need for artificial lighting too. LEDs (Light Emitting Diodes) are increasingly used as a source of light for plants. Among their advantages are, long life, energy efficiency and the capability of programming light wavelengths to better manage the photoperiod. (Al-Kodmany, 2018)

The purpose of quantifying the energy flows is to determine how much energy is needed to meet the demand and whether renewable energy can meet it. In vertical farming the dimensions and proportions of the building footprint is correlated to whether the energy demand can be met by renewable energy. The larger the footprint, the larger the lighting and water requirements but also the energy available. The opposite also applies, the smaller the footprint the lower the demand but also the amount of energy 
available is reduced. Al-Chalabi (2015) studied the feasibility of the building footprint for a vertical farm 33 levels high. A vertical farm with a footprint up to 20x20 m does not require artificial lighting. Up to $23 \times 23 \mathrm{~m}$ the vertical farm requires lighting but is still feasible by means of renewable energy. Between 25x25m to 30x30m footprint, the energy deficit increases exponentially: for $25 \mathrm{~m}$ the number of solar panels required are as much as twice the amount that could be fit in the envelope, whereas for $30 \mathrm{~m}$ the number of solar panels required is four times the amount that could fit. (Al-Chalabi, 2015)

The implementation of vertical farming at the scale of the urban block requires taking into consideration the number of sunlight that each area of the block is going to receive. The land-use at the ground floor level is divided between green landscape and built. The proportion between landscape and built follows the planning requirements in Singapore which is a minimum of 30\% at the ground floor level (Urban Redevelopment Authority, 2018). The parametric model generates the volume that should not be blocked for the green space to receive a specified amount of direct solar access during a certain time of the year. This concept is the reverse of the solar envelope and allows to secure minimum hours of sunlight for the vertical farm to be self-sufficient.

\subsection{Dynamic System Modeling and the Development of Artificial Environments in Singapore}

As described above System Dynamic (SD) was initially introduced by Forrester in the sixties. It is a method to simulate the behavior of a complex system over time mimicking the real system. SD converts the whole system into interconnected series of stocks and flows, which interact between each other according to functional relationship. It can be implemented for different systems at various scales from local to national to global. SD is based on the following principles: 1) system boundary which is a crucial property in understanding and identifying the internal and external dynamics of a complex system. 2) Hierarchy which determines the appropriate level of model according to the purpose of the model. 3) The feedback loops principle is a modeling technique which facilitates the simulation of complex systems. 4) Stocks and flows, this principle enables to quantitively simulate processes, where stocks represent the current state of the system and are the basis for actions and change by flows.

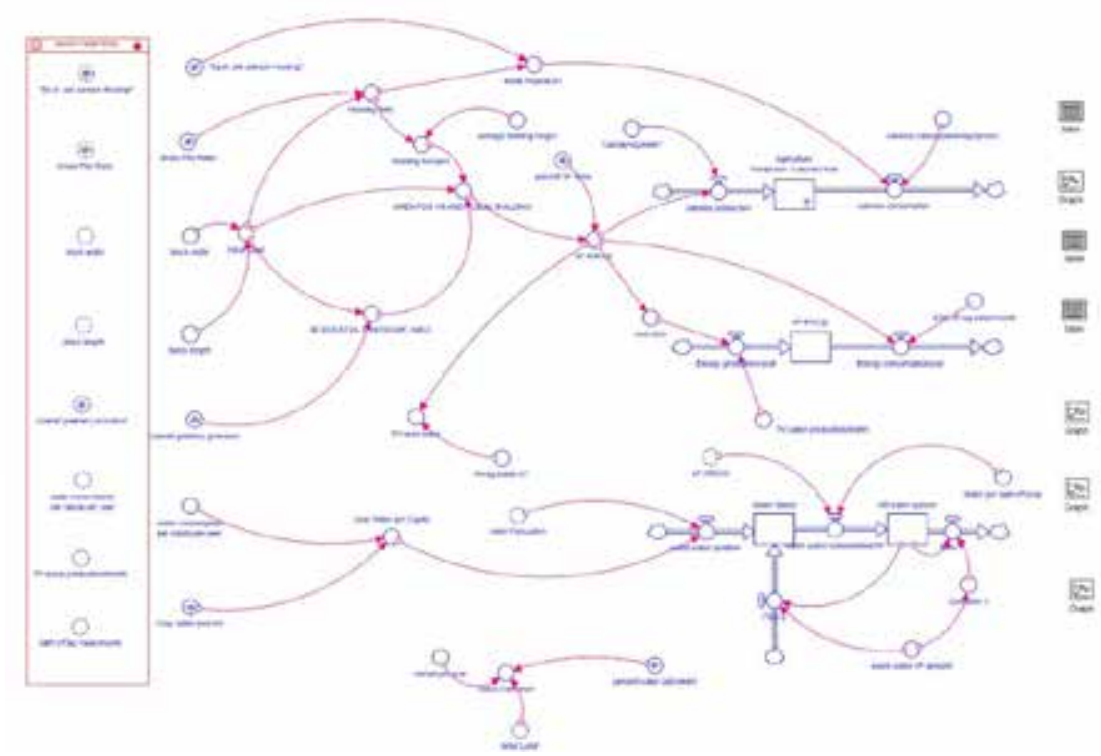

Figure 03. 


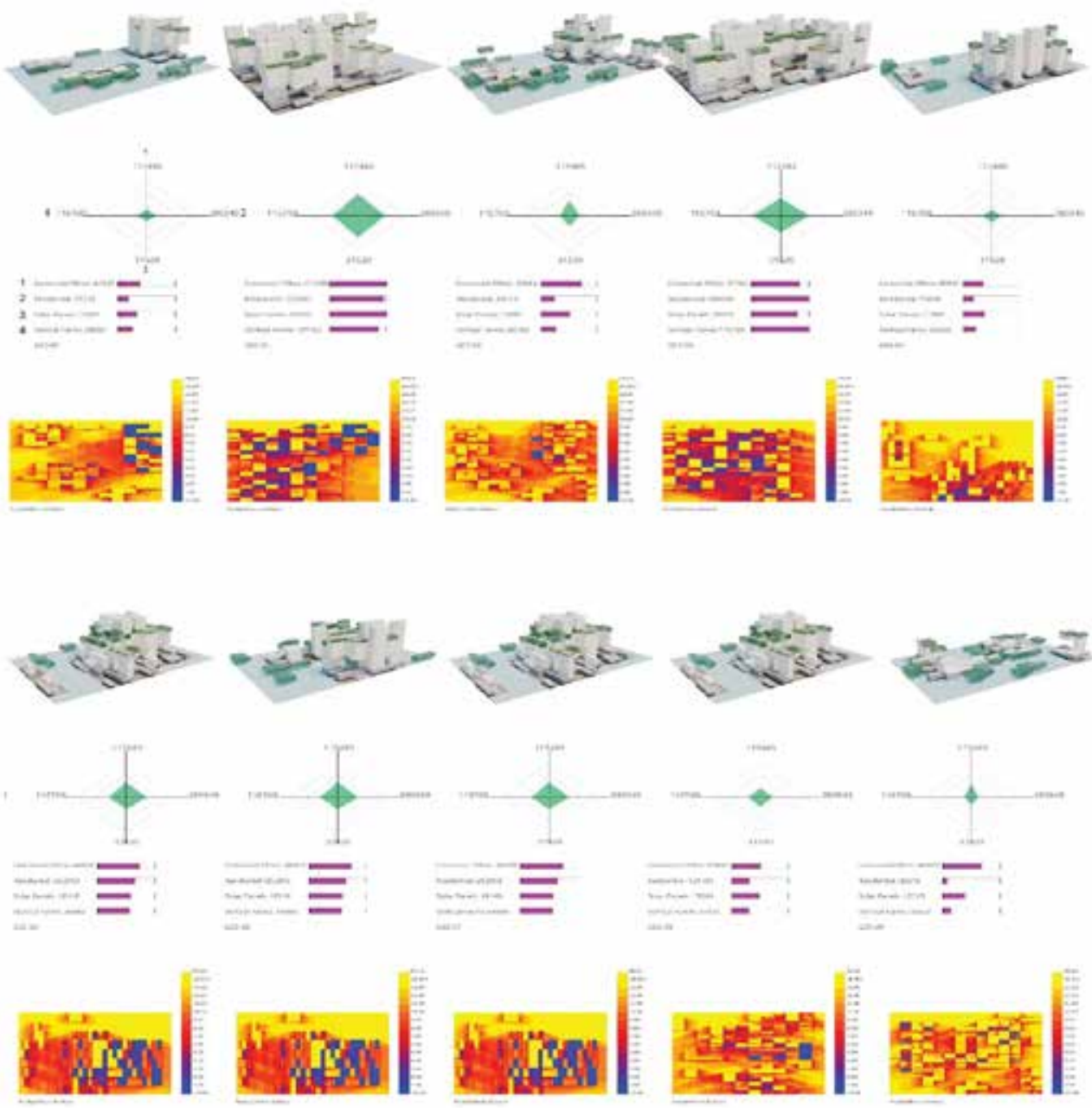

Figure 04.

The SD modeling assumes that every real system can be modeled as a system of equations describing relationship between interconnected flows and stocks. The stock flow is shown in the following equation [1]. The structure of the SD model is often broken into different aggregated sub-systems. The relationships between these sub-systems compose the whole system by a network of stocks, flows and feedback loops. Identifying and recognizing the key components and feedback loops within the system is crucial to the efficiency and accuracy of the model. The methodology of designing SD model could be concisely described in four stages (Pejić-Bach \& Čerić, 2007). (1) The problem definition and articulation which addresses the values of the stocks and the processes between them are determined by the flows. (2) The model conceptualization and hypothesis formulation determine the dynamics of the system and the feedback loops. (3) The formulation of mathematical algorithms. (4) The model verification and validation enabling the testing of the dynamic hypothesis at different scenarios including sensitivity analysis and multi-objective optimization.

For the experiment developed in this paper, the purpose of the (SD) is to generate the numeric data needed as objective for the parametric design model. The initial phase of the modeling process is to define the main elements of the system: in this case, population, vertical farming, energy production 
and water management. The population data is determined according to two existing parameters: (1) the maximum gross plot ratio and (2) the housing area per capita. The population and the block dimensions determine the minimum green and public space within the block. Once defined the main elements of the system, mathematical equations establish the interrelationship between these elements. The system hypotheses consist of producing enough food measured in calories for the given population and generating sufficient energy to meet the demand and reuse the wastewater for irrigation.
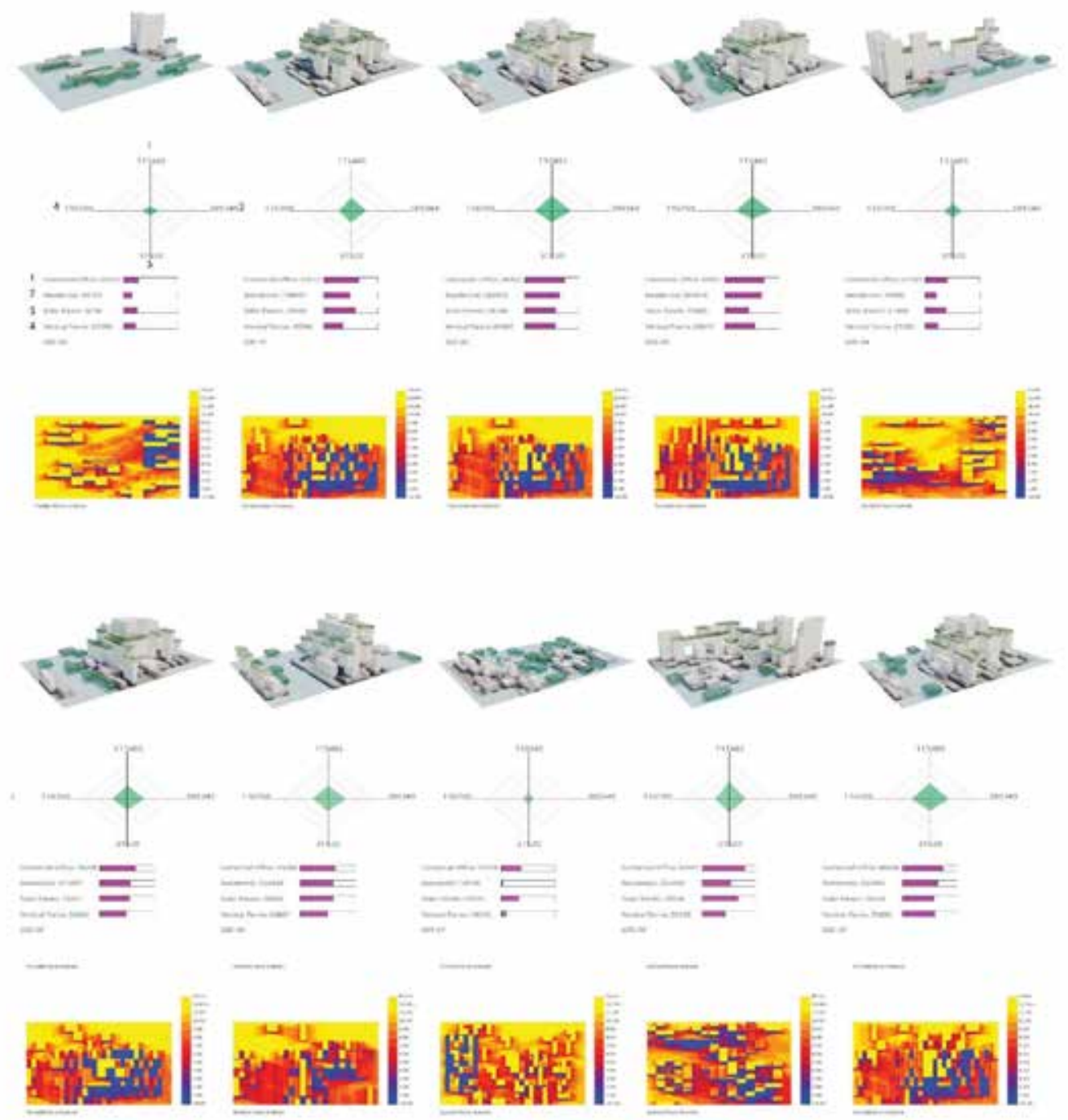

Figure 05.

One of the objectives of the experiment is to search for a set of scenarios that describe different behaviors of the system. This is conducted by employing the sensitivity analysis method. For the presented experiment, four parameters are tested against a specific value range. These parameters are: the living space per capita, the gross plot ratio, overall greenery provision and the percentage of vertical farm area from the total green area. The SD generated two hundred fifty-six solutions. Graph (02) shows the values of vertical farm production for each scenario. In the evaluation, solutions with negative value of production are eliminated because they do not meet the objective of self-sufficiency. Graph (01) shows the ratio between population and food production. 


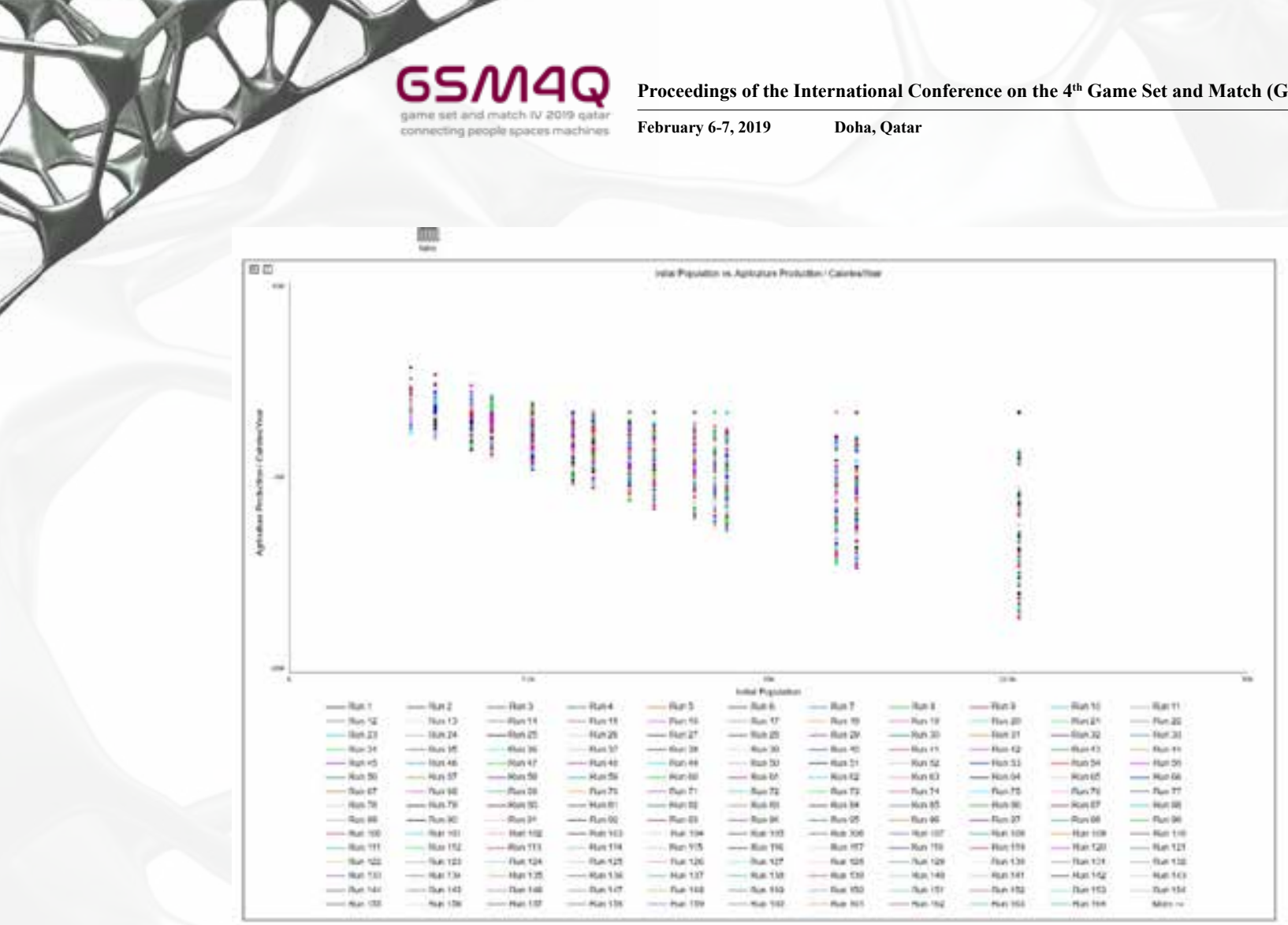

\section{Graph 01}

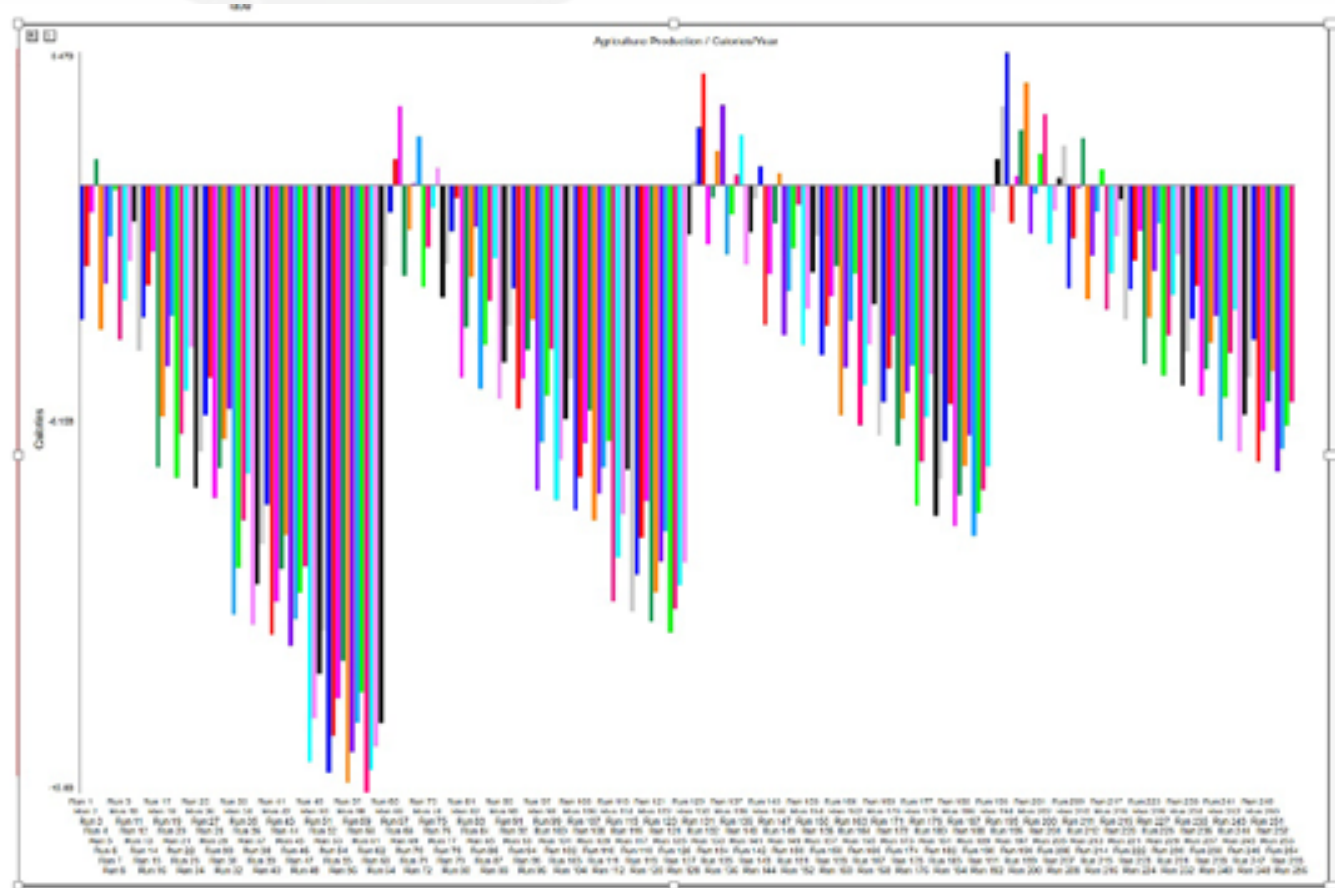

Graph 02

The final step is to process and evaluate the system outcomes and discuss its implications on the productivity of the system. The selected solutions comply with the following criteria: (1) Fall within the population range of 7.000-10.000 people and (2) provide enough vertical farm to be considered self-sufficient. The solution with the largest population from the selected ones were chosen as the preferred. Table (01) shows 
the values of all solutions that meet the criteria described above; the ones highlighted in yellow will be exported to the parametric design model as a criterion for optimization in order to generate urban form.

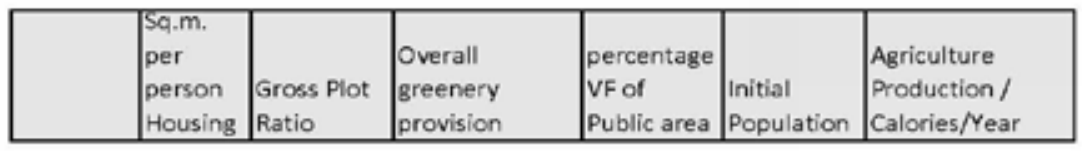

\begin{tabular}{|c|c|c|c|c|c|c|}
\hline Run 1 & 15 & 1.4 & 0.15 & 0.25 & 7611 & 2773.45 \\
\hline Run 2 & 15 & 1.4 & 0.15 & 0.42 & 7611 & 2773.45 \\
\hline Run 3 & 15 & 1.4 & 0.15 & 0.58 & 7611 & 2773.45 \\
\hline Run 4 & 15 & 1.4 & 0.15 & 0.75 & 7611 & 2773.45 \\
\hline Run 145 & 25 & 2.3 & 0.15 & 0.25 & 7611 & 2275.09 \\
\hline Run 146 & 25 & 2.3 & 0.15 & 0.42 & 7611 & 2275.09 \\
\hline Run 147 & 25 & 2.3 & 0.15 & 0.58 & 7611 & 2275.09 \\
\hline Run 148 & 25 & 2.3 & 0.15 & 0.75 & 7611 & 2275.09 \\
\hline Run 5 & 15 & 1.4 & 0.25 & 0.25 & 7611 & 1705.54 \\
\hline Run 6 & 15 & 1.4 & 0.25 & 0.42 & 7611 & 1705.54 \\
\hline Run 7 & 15 & 1.4 & 0.25 & 0.58 & 7611 & 1705.54 \\
\hline Run 8 & 15 & 1.4 & 0.25 & 0.75 & 7611 & 1705.54 \\
\hline Run 149 & 25 & 2.3 & 0.25 & 0.25 & 7611 & 1207.18 \\
\hline Run 150 & 25 & 2.3 & 0.25 & 0.42 & 7611 & 1207.18 \\
\hline Run 151 & 25 & 2.3 & 0.25 & 0.58 & 7611 & 1207.18 \\
\hline Run 152 & 25 & 2.3 & 0.25 & 0.75 & 7611 & 1207.18 \\
\hline Run 9 & 15 & 1.4 & 0.35 & 0.25 & 7611 & 637.62 \\
\hline Run 10 & 15 & 1.4 & 0.35 & 0.42 & 7611 & 637.62 \\
\hline Run 11 & 15 & 1.4 & 0.35 & 0.58 & 7611 & 637.62 \\
\hline Run 12 & 15 & 1.4 & 0.35 & 0.75 & 7611 & 637.62 \\
\hline Run 153 & 25 & 2.3 & 0.35 & 0.25 & 7611 & 139.26 \\
\hline Run 154 & 25 & 2.3 & 0.35 & 0.42 & 7611 & 139.26 \\
\hline Run 155 & 25 & 2.3 & 0.35 & 0.58 & 7611 & 139.26 \\
\hline Run 156 & 25 & 2.3 & 0.35 & 0.75 & 7611 & 139.26 \\
\hline Run 225 & 30 & 3.3 & 0.15 & 0.25 & 8880 & 850.69 \\
\hline Run 226 & 30 & 3.3 & 0.15 & 0.42 & 8880 & 850.69 \\
\hline Run 227 & 30 & 3.3 & 0.15 & 0.58 & 8880 & 850.69 \\
\hline Run 228 & 30 & 3.3 & 0.15 & 0.75 & 8880 & 850.69 \\
\hline Run 81 & 20 & 2.3 & 0.15 & 0.25 & 9514 & 886.02 \\
\hline Run 82 & 20 & 23 & 0.15 & 0.42 & 9514 & 886.02 \\
\hline Run 83 & 20 & 2.3 & 0.15 & 0.58 & 9514 & 886.02 \\
\hline Run 84 & 20 & 2.3 & 0.15 & 0.75 & 9514 & 886.02 \\
\hline
\end{tabular}

\section{Multi-Objective Optimization Model}

The second step of the experiment is to generate a population of urban block morphologies based on the DS output data. The aim of the experiment is to generate the fittest solution using an evolutionary algorithm towards multiple conflicting objectives. The evolutionary algorithm behind the solver is the Strength Pareto Evolutionary Algorithm 2 (SPEA2), which mimics a natural evolution including variation and selection strategies, which are applied to a population. The algorithm evaluates and select a set of candidate solutions in each generation, and the parameters that were set in the solver are (1) number of generation (iteration):10. (2) Number of individuals in each generation: 1.0 (3) Crossover rate: 0.8. (4) Elitism: 0.5. (5) Mutation Probability: 0.2. (6) Mutation rate: 0.9.

The model departs from the urban block (350X233 meters). The allocation of urban massing follows the principles of solar radiation, allowing a minimum hour of solar exposure of the green areas at the ground level. The multi-criteria for optimization are: 1) maximizing vertical farming area, to achieve higher productivity 2) maximizing the green area, to provide public and social space 3) maximizing residential buildings area 4) maximizing distance between building clusters, thus increasing the area of open space between the buildings. These objectives are contradictory because they all compete to occupy more area of the block. 
When the transformation actions on the block are defined, there is a direct correlation between them and the fitness objectives. For the evolutionary algorithm, these actions are the genome of the model that define the genetic code of the evolutionary process. The actions are as follows: 1) the height of the vertical farms, 2) the footprint in percentage of the vertical farms related to the green area 3 ) the size of the unit 4) the percentage of the build area, and 5) the average hours of sunlight exposure on the green area and vertical farms. The parametric model was defined to allow the development of vertical farms at the ground level and on the rooftops and balconies.

\section{Findings and Analysis}

The simulation generates 10 generation with 10 solutions (individuals), three generation are chosen for analysis. The analysis of the morphology of each solution is carried on by two methods, visually and quantitively. The quantitively analysis is a key factor in determining the selection of the optimal solutions. Algorithm was run on each selected solution to generate a quantitative data. The data extracted are: 1) The total area of vertical farming. 2) The total area of solar panels. 3) The total area of residential buildings. 4) Solar radiation. The analysis aims to identify the solution that falls in the criteria that was generated by the DS simulation.

From the analysis, it is apparent that in generation 3 there was a wide variation within the population; the results were notably different. Three solutions meet the initial quantitative objectives, but the morphology evolved towards clustering most of the building in one cluster. Therefore, all the solutions in this generation were dismissed. In generation 6, the solutions evolved in lesser variation than in generation 3. In some solutions, value of the residential was too low, for example, solution G6-07 has the lowest value for residential area of all the generation. In this generation, there are the largest fittest number of solutions, six in number. However, the one with the highest values within the objective range and greater number of clusters was number G6-08. This solution was selected as the fittest. Lastly, generation 09: the convergence tendency within the population increased and the results were closed. The three fittest solutions were the closet to the SD objectives, in terms of morphology just one solution fit the clustering objective. Solution number G9-08 was selected. The analysis process results in selecting 2 solutions for further design development and modifications solution G05-08 and G09-05. The model determined the number of hours of sunlight required at the ground level is 5 hours.

\begin{tabular}{|l|l|l|l|l|}
\hline Objective & DS Values & G03 & G05-08 & G09-05 \\
\hline Housing Area & 190283 & ----- & 204435 & 180185 \\
\hline Vertical Farms Area & 44900 & ----- & 502954 & 45370 \\
\hline Solar Panels Area & 8100 & ---- & 50236 & 18926 \\
\hline Number of hours of sunlight & 5 & 5 & 5 & 5 \\
\hline
\end{tabular}

\section{Conclusion}

The experiment shows the advantages of integrating two modeling methods in the urban design process, namely the DS modeling and the parametric design model. The DS model generates multiple scenarios of artificial environments in Singapore according to sensitivity analysis. While the parametric design model generates a set of optimized solutions to fit the performance of the urban systems. The integration of these two methods could increase the potential of the urban blocks to function as a productive system. The experiment demonstrates that it is possible to achieve self-sufficiency by integrating vertical farming as integral part of the urban block. Five hours of sunlight at the ground level are the optimum value generated by the model. The presented model is based on general data, estimations and limited number of generations in evolutionary computation. The more detailed the DS model the closer to the real system. Increasing the amount of the generation and size of the population in the evolutionary process could increase the convergence to the fittest solution. 


\section{Bibliography}

Al-Chalabi, M. (2015). Vertical farming: Skyscraper sustainability? Sustainable Cities and Society, 18, 74-77.

Alexandratos, N., \& Bruinsma, J. (2012). World agriculture towards 2030/2050: the 2012 revision. ESA Working paper FAO, Rome.

Al-Kodmany, K. (2018). The vertical farm: A review of developments and implications for the vertical city. Buildings, 8,24 .

Batty, M. (2013). The New Science of Cities. The MIT Press.

Batty, M. (2008). The size, scale, and shape of cities. Science, 319, 769-771.

Bratton, B. H. (2016). The stack: On software and sovereignty. MIT press.

Despommier, D. (2009). The rise of vertical farms. Scientific American, 301, 80-87.

Forrester, J. W. (1997). Industrial dynamics. Journal of the Operational Research Society, 48, 1037-1041.

Fujita, M., \& Krugman, P. (2004). The new economic geography: Past, present and the future. Papers in regional science, 83, 139-164.

Kalantari, F., Mohd Tahir, O., Mahmoudi Lahijani, A., \& Kalantari, S. (2017). A Review of Vertical Farming Technology: A Guide for Implementation of Building Integrated Agriculture in Cities. Advanced Engineering Forum, $24,76-91$. https://doi.org/10.4028/www.scientific.net/AEF.24.76.

Ljung, L. (1998). System identification, in: Signal Analysis and Prediction. Springer, 163-173.

Llabres, E., \& Rico, E. (2012). In progress: Relational urban models. Urban Design International, 17, 319-335.

Mitchell, M. (2011). Complexity: A Guided Tour. Oxford University Press, U.S.A.

Hilberseimer, L. (1949). New Regional Pattern: Industries and Gardens, Workshops and Farms.

Pejić-Bach, M., \& Čerić, V. (2007). Developing system dynamics models with” step-by-step” approach. Journal of information and organizational sciences, 31, 171-185.

Rassia, S. T., Pardalos, P. M., \& Despommier, D. (2012). Sustainable environmental design in architecture: impacts on health. Springer Science \& Business Media.

Urban Redevelopment Authority. (2018). Residential Handbook.

Waldheim, C. (2010). Notes toward a history of agrarian urbanism. Places Journal.

Wright, F. L. (1932). The disappearing city. WF Payson.

Cite this article as: Aiman T., Enriqueta L.V., "The Agrarian City in the age of Planetary Scale Computation: Dynamic System Model and Parametric Design Model for the introduction of Vertical Farming in High Dense Urban Environments in Singapore", International Conference on the $4^{\text {th }}$ Game Set and Match (GSM4Q-2019), Doha, Qatar, 6-7 February 2019, https://doi.org/10.29117/gsm4q.2019.0018 